\title{
FONDOS DE INVERSIÓN INMOBILIARIA Y DERECHO INTERNACIONAL PRIVADO EUROPEO: REFLEXIONES AL HILO DE LA STJUE DE 3 DE OCTUBRE DE 2019, VEREIN FÜR KONSUMENTENINFORMATION, C-272/18
}

\author{
REAL ESTATE INVESTMENT FUNDS AND EUROPEAN \\ PRIVATE INTERNATIONAL LAW: NOTES ON \\ THE JUDGEMENT OF THE COURT OF 3 OCTOBER 2019, \\ VEREIN FÜR KONSUMENTENINFORMATION, C-272/18
}

\author{
Eva JimÉNEZ PALMA \\ Profesora de Derecho internacional privado \\ Universidad de Málaga \\ ORCID ID: 0000-0002-5842-9470
}

Recibido: 15.06.2021 / Aceptado: 08.07.2021

DOI: https://doi.org/10.20318/cdt.2021.6295

\begin{abstract}
Resumen: La actualidad y relevancia del asunto C-272/18 radican principalmente en que se trata de la primera ocasión en la que el TJUE se pronuncia sobre el tratamiento que la «fiducia inmobiliaria de inversión» ha de recibir en sede de ley aplicable. En la sentencia se analiza, en esencia, si estos entramados fiduciarios se subsumen en el ámbito material del Reglamento Roma I, distinguiendo para ello entre cuestiones contractuales y cuestiones societarias. En relación a las primeras, se examina si resultan de aplicación las normas de protección de consumidores insertas en dicho instrumento europeo, prestando especial atención a la exclusión prevista en su art.6.4.a) "servicios prestados exclusivamente en un país diferente al de la residencia habitual del consumidor", así como la autonomía conflictual regulada en su apartado segundo, en relación con la Directiva 93/13/CEE.
\end{abstract}

Palabras clave: fiducia y fondos de inversión inmobiliaria, derecho aplicable, contratos de consumo, prestación de servicios a distancia, autonomía conflictual.

Abstract: The actuality and relevance of Case C-272/18 lies mainly on the fact that it is the first time that the Court of Justice has ruled on the treatment that the «real estate investment funds» must receive in the area of applicable law. In essence, it is analyzed whether these fiduciary structures are submitted within the material scope of the Rome I Regulation, distinguishing between contractual and corporate matters. In relation to the first one, it is examined whether are applicable the consumer protection rules inserted in that instrument, paying special attention to the exclusion provided for in its article 6.4.a) "services provided exclusively in a country other than that of the habitual residence of the consumer" and the choice of law regulated in its second section, in relation to Directive 93/13/EEC.

Keywords: fiducia \& real estate investment funds, applicable law, consumer contracts, electronic provision of services, choice of law in private international law.

Sumario: I. Introducción. II. Litigio principal y cuestiones prejudiciales planteadas. III. Entramado de relaciones jurídicas: aspectos contractuales versus aspectos societarios. 1. Los fondos de inversión inmobiliaria como «operaciones complejas» de naturaleza fiduciaria. 2. Repercusiones 
sobre el ámbito material del Reglamento Roma I: problemas de calificación. 3. Alcance del artículo $1.2^{\circ}$.f) del Reglamento Roma I. 4. Aspectos societarios presentes en los fondos de inversión inmobiliaria controvertidos. IV. Fondos de inversión inmobiliaria y régimen de protección de consumidores del Reglamento Roma I. 1. Los contratos fiduciarios y el artículo 6.1 del Reglamento Roma I. 2. Exclusión prevista en el art. 6.4.a) del Reglamento Roma I: servicio fiduciario prestado "exclusivamente" en un Estado diferente al de la residencia habitual del consumidor. 3. Licitud de las cláusulas de elección de ley insertas en los contratos fiduciarios celebrados con consumidores. V. Conclusiones.

\section{Introducción}

1. Las cuestiones prejudiciales planteadas en la sentencia de 3 de octubre de 2019 (C-272/18) ${ }^{1}$ fueron presentadas en el contexto de un litigio suscitado entre Verein für Konsumenteninformation (asociación de consumidores sin ánimo de lucro con domicilio social en Austria, en adelante «VKI») y TVP Treuhand- und Verwaltungsgesellschatf für Publikumsfonds mbH \& Co KG (sociedad fiduciaria con domicilio social en Hamburgo, en adelante «TVP»), en relación con la licitud de una cláusula de elección de ley aplicable que esta utiliza en contratos fiduciarios celebrados con inversores privados residentes en Austria.

2. Esta sentencia resulta de gran interés por diversos motivos. En términos generales, se puede afirmar que se trata de la primera ocasión en la que el Tribunal de Justicia de la Unión Europea se pronuncia sobre el tratamiento que recibe la fiducia inmobiliaria de inversión en Derecho internacional privado europeo; concretamente, en sede de ley aplicable. En este contexto, el Tribunal de Justicia analiza, en esencia, dos cuestiones o dificultades preliminares: de una parte, si dicha operación fiduciaria se subsume en el ámbito de aplicación material del Reglamento (CE) 593/2008 (Reglamento Roma I)²; de otra, si a los aspectos que superan efectivamente el primer test, les resulta aplicable el régimen de protección de consumidores contemplado en dicho instrumento normativo.

3. En relación al ámbito del Reglamento, y con el fin de esclarecer si la fiducia inmobiliaria de inversión queda incluida en el elenco de materias a las que resulta aplicable el Reglamento, el Tribunal de Justicia delimita qué cuestiones son contractuales y cuáles son societarias, prestando especial atención para ello al artículo 1, apartado segundo, letra f), que excluye de su ámbito de aplicación «las cuestiones pertenecientes al Derecho de sociedades, asociaciones y otras personas jurídicas».

4. Con respecto al régimen de protección de los contratos de consumo previsto en el Reglamento Roma I, en esta resolución se examinan diversas cuestiones de interés. Partiendo de una breve alusión al concepto de «contrato de consumo» (artículo 6), el Tribunal de Justicia analiza en profundidad el alcance de la exclusión prevista en el apartado cuarto, letra a) de dicho precepto, en virtud del cual las normas de protección en materia de consumo no se aplicarán a los "contratos de prestación de servicios, cuando los servicios deban prestarse al consumidor, exclusivamente, en un país distinto de aquel en que el mismo tenga su residencia habitual". Por último, y sobre la base del célebre asunto C-191/15², se examina la licitud de la cláusula de elección de ley aplicable inserta en los contratos fiduciarios controvertidos, analizando para ello el artículo 6, apartado segundo, del Reglamento y, a la luz de éste, el artículo 3, apartado primero, de la Directiva 93/13/CEE sobre las cláusulas abusivas en los contratos celebrados con consumidores ${ }^{4}$.

\footnotetext{
${ }^{1}$ STJUE de 3 octubre de 2019, Verein für Konsumenteninformation (C-272/18, EU:C:2019:827).

2 Reglamento (CE) núm. 593/2008, del Parlamento Europeo y del Consejo, de 17 de junio, sobre la ley aplicable a las obligaciones contractuales (Roma I), DO L 177 de 4 de julio de 2008.

3 STJUE de 28 julio de 2016, Verein für Konsumenteninformation (C-191/15, EU:C2016:612).

4 Directiva 93/13/CEE del Consejo, de 5 de abril de 1993, sobre las cláusulas abusivas en los contratos celebrados con consumidores (DOUE L 1993 80526).
} 
5. Ante la relevancia de tales cuestiones -unas más novedosas, otras quizás más conocidas-, resulta oportuno dedicar unas páginas a abordar los problemas que plantean, ofreciendo, desde una perspectiva crítica, algunas reflexiones -tanto teóricas como prácticas- en torno a la doctrina del Tribunal de Justicia derivada de este asunto.

\section{Litigio principal y cuestiones prejudiciales planteadas}

6. TVP es una sociedad fiduciaria con domicilio social en Hamburgo que, en su condición de filial al 100\% del «grupo MPC», crea y comercializa fondos de inversión inmobiliaria en diferentes países $^{5}$. En el litigio principal, el fondo de inversión en cuestión (denominado «Fondo 43») se había constituido en el año 2003 -en forma de sociedad comanditaria sometida al Derecho alemán-, y comercializado tanto en Alemania cuanto en otros países como Austria. Sus estatutos sociales facultaban a TVP a incorporar a nuevos inversores como socios comanditarios (artículo 3, apartado tercero).

7. Los inversores residentes en Austria que deseaban participar en tales fondos debían enviar a TVP una declaración de adhesión -en forma de oferta de celebración de contrato fiduciario-, e ingresar el importe de su participación en la cuenta fiduciaria del fondo elegido, abierta a nombre de TVP en un banco austriaco. Al firmar estos contratos fiduciarios (Treuhandvertrags) regidos por el derecho alemán ${ }^{6}$,

\footnotetext{
${ }^{5}$ Para mayor profundización sobre este tipo de operaciones comerciales, véase la nota 9 de las conclusiones del Abogado General y referencias citadas, en las que -siguiendo las observaciones de VKI- afirma que el uso de este tipo de fondos de tipo cerrado -particularmente extendido en Alemania- consiste en reunir capital, mediante la creación y venta de las participaciones en el capital de sociedades constituidas a tal fin, para invertir en bienes inmobiliarios, a fin de generar ingresos mediante el arrendamiento y la venta de tales inmuebles. En cuanto a la regulación de los fondos de inversión inmobiliaria en el sistema jurídico español, debemos tener en cuenta la Ley 5/2021, de 12 de abril, por la que se incorpora al ordenamiento interno la Directiva (UE) 2017/828 del Parlamento Europeo y del Consejo de 17 de mayo de 2017; y por la que se modifica la Ley 35/2003, de 4 de noviembre, de Instituciones de Inversión Colectiva y la Ley 22/2014, de 12 de noviembre, de entidades de capital-riesgo, otras entidades de inversión colectiva de tipo cerrado y las sociedades gestoras de entidades de inversión colectiva de tipo cerrado.

${ }^{6}$ Como ha señalado el Abogado General en el punto 24 de sus conclusiones, "en el marco de una operación de Treuhand, una persona a la que se denomina «fiduciante» (Treugeber) transfiere la titularidad de activos a otra persona denominada «fiduciaria» (Treuhänder), la cual debe mantener estos activos separados de su propio patrimonio y administrarlos con una finalidad determinada a favor de un beneficiario (que puede ser el fiduciante, aunque no necesariamente). En su condición de titular de los activos transferidos, el fiduciario actúa en nombre propio, pero por cuenta del beneficiario". Merece especial atención la nota 11 de dichas conclusiones, en las que el AG afirma que "la Treuhand y la fiducia son similares al trust propio de los países del Common Law”. Apoyándose en el Informe Giuliano-Lagarde (DO 1980, C 282, p.13), añade que, si bien es cierto que el Reglamento Roma I excluye de su ámbito de aplicación material la constitución de trusts y las relaciones entre constituyentes, administradores y beneficiarios (artículo 1, apartado segundo, letra h), tal exclusión no abarca las "instituciones similares de Derecho continental". Aunque no me detendré en ello, puesto que excede del objetivo de este trabajo, deben ser puestas de relieve algunas consideraciones generales. Es común en la doctrina estudiar estas instituciones desde una perspectiva comparada, analizando las semejanzas y diferencias que presentan entre sí. No obstante, resulta muy difícil acordar cuáles son sus características esenciales. Incluso se discute qué son "fiducias", "fideicomisos", "trusts" y qué no. De hecho, emplear tales términos ya conlleva notables dificultades inherentes. Además, no se debe perder de vista que se trata de instituciones que están cambiando y evolucionando constantemente. Algunos autores consideran que el estudio de estas figuras jurídicas y del alcance de las mismas constituye uno de los esfuerzos más apasionantes para entender las posibles diferencias existentes entre distintas familias jurídicas: common law, civil law y mixed legal jurisdictions. Así, es frecuente caracterizar tales instituciones en función del sistema jurídico en el que se localicen, esto es, según si se trata de un sistema rígido o cerrado o, por el contrario, de un sistema abierto. Por ejemplo, considerar la propiedad como inequívoca, consolidada y absoluta lleva, según parte de la doctrina, al difícil entendimiento de la noción de trust y de su alcance. Asimismo, se ha entendido generalmente que los elementos fundamentales de la institución angloamericana son contrarios a los principios básicos de la civil law doctrine. Por el contrario, otros autores sostienen que el principio de numerus clausus de los derechos reales y la mayor parte de las razones que se esgrimen para mostrar las dificultades que presentaría la inserción de los trusts en los sistemas romano-germánicos parecen tan incomprensibles y arcaicos a los juristas angloamericanos como lo es la distinción entre el common law y la equity para los juristas continentales. Para profundizar sobre estas ideas, veánse, entre otros, A. BRAUN, "The State of the Art of Comparative Research in the Area of Trusts", en M. Graziadei y L. SMith, (eds), Comparative Property Law: Global Perspectives, Cheltenham, Edward Elgar Publishing, 2017; A. Braun y W. Swadling, "Management Devices: Trust, Treuhand, Fiducie", en S. VAN Erp y B. Akrermans (eds.), Cases, Materials and Text on National, Supranational and International Property Law, Hart Publishing, 2012, pp. 553, ss; W.W. Buckland y A.D. Mcnair, Roman Law \& Common Law: A Comparison in Outline, Cambridge, Cambridge University Press, 1952, p. 176; E. GaIllard, "Les enseignements de la Convention de la Haye du 1er juillet 1985
} 
los inversores entraban en el fondo indirectamente en calidad de fiduciantes. TVP, por su parte, prestaba los correspondientes servicios fiduciarios consistentes en gestionar las participaciones comanditarias en nombre propio, pero por cuenta de los fiduciantes; y remitiendo a estos los dividendos y demás ventajas patrimoniales derivadas de su participación.

8. Los modelos de contrato utilizados por la sociedad fiduciaria incluían una cláusula no negociada de forma individual que disponía lo siguiente: "[E]l presente contrato se rige por el Derecho de la República Federal de Alemania. El lugar de cumplimiento y el fuero judicial para todo litigio derivado del presente contrato y en relación con su celebración es el correspondiente al domicilio social de la fiduciaria, siempre que este pacto esté permitido por la ley".

9. Esta cláusula constituye, precisamente, el objeto del litigio principal, y es que VKI (asociación de consumidores austriaca) interpuso el 6 de septiembre de 2013 una acción de cesación ante los tribunales vieneses solicitando que se prohibiera a TVP -a efectos de sus relaciones comerciales con inversores residentes en Austria- utilizar la cláusula anteriormente citada, por considerar que infringe tanto el Derecho de la Unión Europea como el Derecho austriaco (aplicable, en su opinión, con arreglo al Reglamento Roma I: lugar de prestación de los servicios).

10. Si bien el tribunal de primera instancia (Handelsgericht Wien) estimó la demanda y ordenó a TVP que dejara de utilizar tales cláusulas, el tribunal de apelación (Oberlandesgericht Wien) anuló la sentencia y le devolvió el asunto para que prosiguiera la instrucción y adoptara una nueva resolución. Ambas partes recurrieron esta resolución ante el Tribunal Supremo (Obester Gerichtshof), quien decidió suspender el procedimiento y plantear ante el Tribunal de Justicia las siguientes cuestiones prejudiciales:

«1) ¿Están comprendidos en la exclusión del ámbito de aplicación que prevén el artículo 1, apartado 2, letra e), del [Convenio de Roma] y el artículo 1, apartado 2, letra f), del [Reglamento Roma I] los acuerdos entre un fiduciante y un fiduciario, tenedor de una participación en una sociedad comanditaria por cuenta del fiduciante, en particular cuando existe una trama de contratos societarios y fiduciarios?

2) En caso de respuesta negativa a la primera cuestión:

¿Debe interpretarse el artículo 3, apartado 1, de la [Directiva sobre las cláusulas abusivas] en el sentido de que es abusiva una cláusula incluida en un contrato fiduciario celebrado entre un empresario y un consumidor para la administración de una participación comanditaria, cláusula que no fue negociada individualmente y que establece como Derecho aplicable el del país en que se encuentra el domicilio social de la sociedad comanditaria, cuando la única finalidad del contrato fiduciario es la administración de dicha participación comanditaria, incumbiendo al fiduciante los derechos y obligaciones de un socio directo?

3) En caso de respuesta afirmativa a la primera o a la segunda cuestión:

¿Es distinta la respuesta si el empresario, para prestar los servicios a los que se ha comprometido, no tiene que desplazarse al país del consumidor, pero está obligado a remitir al consumidor los dividendos y demás ventajas patrimoniales derivadas de la participación, así como información

relative à la loi applicable au trust et à sa reconnaissance", Revue Juridique et Politique, vol. 44, 1990, p. 305; M. GrAZIADEI, U. Mattei y L. Smith, Commercial Trusts..., ; H. Hansmann y U. Mattei, "The functions of Trust Law: A Comparative Legal and Economic Analysis", New York University Law Review, 73, pp. 434-435; D. HAYTON, Extending the boundaries of trusts and similar ring-fenced funds, The Hague, Kluwer Law International, 2002; P. LEPAulle, "Civil Law Substitutes for Trusts", Yale Law Journal 36, 1926, pp. 1226, ss.; M. LuPoI, Trusts: A Comparative Study, Cambridge, Cambridge University Press, 2000; F. Maitland, Equity: A Course of Lectures, Cambridge, Cambridge University Press, 1936, p. 23; T.B. Sмith, "Mixed Jurisdictions: Trusts, Fideicommissa and Trustlike Institutions", en F.H. LAwson (ed.), International Encyclopedia of Comparative Law. Structural Variations in Property law, Vol 6, Tübingen, Mohr, 1973, párrafos 262-267. 
sobre el curso de los negocios relativos a la participación? ¿Tiene alguna incidencia a este respecto la circunstancia de que resulten de aplicación el Reglamento Roma I o el Convenio de Roma?

4) En caso de respuesta afirmativa a la tercera cuestión:

¿Se mantiene inalterada esta respuesta si, además, la solicitud de suscripción del consumidor fue firmada en su país de residencia, el empresario también facilita información sobre la participación en Internet y se ha establecido un lugar de pago en el país del consumidor, en el que este debe ingresar el importe de la participación, si bien el empresario carece de facultad de disposición sobre esta cuenta bancaria? ¿Tiene alguna incidencia a este respecto la circunstancia de que resulten de aplicación el Reglamento Roma I o el Convenio de Roma?»

\section{Entramado de relaciones jurídicas: aspectos contractuales versus aspectos societarios}

\section{Los fondos de inversión inmobiliaria como «operaciones complejas» de naturaleza fiduciaria}

11. Actualmente, buena parte de los negocios celebrados en el seno del comercio internacional se articulan jurídicamente como «operaciones económicas complejas», esto es, operaciones formadas por diferentes contratos: un «contrato marco» en el que se regulan los aspectos de base de la relación jurídica (como las obligaciones de las partes) y varios «contratos secundarios o de ejecución» que se celebran generalmente en cumplimiento de las obligaciones pactadas en el primero. Se trata, por tanto, de una red contractual donde los efectos de cada contrato individualmente considerado inciden -directa o indirectamente- en los restantes?

12. Uno de los rasgos más característicos de la fiducia inmobiliaria es precisamente el relativo al fenómeno de la conexidad o agrupamiento contractual. Aunque el «contrato de fiducia» (en sentido estricto) se celebra únicamente entre fiduciante y fiduciario, los «entramados fiduciarios de carácter inmobiliario» ${ }^{8}$ responden a un marco mucho más amplio, resultando de la combinación de numerosas relaciones jurídicas de distinta naturaleza (contractual, societaria, ...) que presentan un nexo funcional entre sí. Si estos negocios ya presentan numerosos problemas -de validez y/o eficacia- en el tráfico interno ${ }^{10}$, todo se complica aún más cuando presentan vínculos con más de un ordenamiento jurídico.

13. En el asunto objeto de análisis, tal y como ha señalado el Abogado General (Saugmandsgaard Øe) en sus conclusiones, la «trama de contratos» controvertida se basa en el hecho de que en los fondos de inversión inmobiliaria (en adelante FII) -constituidos en forma de sociedades comanditarias

7 M.A. Cebrián SAlvat, "Las operaciones contractuales complejas en Derecho internacional privado europeo", $A E D I P r$, t. XVII, 2017, pp. 334-338, quien se decanta por el término "operaciones contractuales complejas", frente a otros como "contrato mixto o complejo", por tratarse de una operación conformada por varios contratos y no solo por uno.

${ }^{8}$ Estos esquemas fiduciarios pueden ser clasificados en atención a numerosos parámetros: i) según la función económica de la obligación asumida; ii) según el bien objeto del negocio; iii) según la naturaleza pública o privada del fiduciante; etc. De forma muy general, cabe afirmar que la fiducia inmobiliaria puede ser de administración, de inversión (por ejemplo, los fondos de inversión inmobiliaria), de garantía o de titulización. Por ser cada vez más conocidos y utilizados en Latinoamérica, véanse, por ejemplo, S.I. Bello Knoll, Fideicomiso público, Buenos Aires, Marcial Pons Argentina, 2013, pp. 171-231; E. Casas SAnz De Santamaría, Del «Trust» anglosajón a la fiducia en Colombia, $3^{\mathrm{a}}$ ed., Bogotá, Temis, 2004, pp. 34-38; A. Estrada Alonso, El fideicomiso y los fondos sin personalidad jurídica: proyección de la cesión en confianza para adscribir patrimonios a un encargo de gestión en el ordenamiento jurídico español, Madrid, Centro de Estudios Ramón Areces, 2010, pp. 149-197; N.P. Etchegaray, Fideicomiso, Buenos Aires, Astrea, 2008, pp. 81-115; L.M. Medina Vanegas y J.A. VÁsquez Torres, "Responsabilidad de las fiduciarias frente a los consumidores inmobiliarios", Universidad Militar Nueva Granada, Bogotá, 2014, pp. 10-18; C.A. Molina Sandoval, El fideicomiso en la dinámica mercantil, Buenos aires, Euros Editores, 2009, pp. 381-503; S. Rodríguez Azuero, Negocios fiduciarios: su significación en América latina, Colombia, Legis, 2017, pp. 399-559.

9 Destacan L.G. Baena CÁrdenas, Fiducia inmobiliaria. Tensión entre la autonomía privada, el derecho a la vivienda digna y el derecho de consumo, Bogotá, Universidad Externado de Colombia, 2017, pp. 38-69; S. Rodríguez Azuero, Negocios fiduciarios..., op. cit., pp. 326-331.

10 Véase supra nota 6. 
conforme al derecho alemán- los contratos societarios de estas sociedades prevén la posibilidad de que los inversores celebren un contrato fiduciario con la sociedad fiduciaria (TVP) y entren de «forma indirecta» en las sociedades en calidad de fiduciantes, recibiendo el mismo trato que el resto de socios «directos» y ostentando, por tanto, las mismas obligaciones y los mismos derechos que estos. La naturaleza compleja de la operación también queda constatada en relación con la remuneración que percibe la fiduciaria (que viene estipulada en los contratos societarios), y en el hecho de que son los propios estatutos de las sociedades los que hacen referencia, en algunas ocasiones, a los contratos fiduciarios ${ }^{11}$.

14. Como se puede intuir, esta no es, sin embargo, una cuestión pacífica. De hecho, las partes litigantes manifiestan diferentes posturas al respecto. Por un lado, VKI considera que los contratos fiduciarios celebrados entre los inversores y la sociedad fiduciaria no se rigen por el Derecho de sociedades, sino por el Derecho de obligaciones. Por el contrario, TVP sostiene que los contratos fiduciarios son indisociables de los contratos societarios, existiendo una única relación jurídica, comprendida íntegramente en la exclusión prevista en el artículo 1, apartado segundo, letra f) RRI.

\section{Repercusiones sobre el ámbito material del Reglamento Roma I: problemas de calificación}

15. Desde el punto de vista del Derecho internacional privado, la principal cuestión que plantean los entramados contractuales es, sin lugar a dudas, la determinación de la ley aplicable. En opinión de algunos autores, se debe descartar una determinación global de la misma, y calificar separadamente cada una de las relaciones jurídicas que integran dicho entramado ${ }^{12}$. Consecuentemente, y salvo pacto en contrario, a cada uno de los negocios autónomos que conforman la operación se le aplicará su correspondiente norma de conflicto -en función de su naturaleza contractual, societaria, real, etc.-, quedando sometida al ordenamiento jurídico que determine la misma ${ }^{13}$.

16. En la sentencia que aquí se comenta no se discute, con carácter general, si los negocios fiduciarios generan «obligaciones contractuales», sino más bien cómo repercute la existencia de tal trama en la identificación del texto aplicable; particularmente, si la exclusión prevista en el artículo 1, apartado segundo, letra f) del Reglamento también comprende las obligaciones contractuales que tienen su origen en un negocio fiduciario que tiene por objeto la administración de una participación en una sociedad comanditaria ${ }^{14}$.

17. Se ha de partir, necesariamente, de dos ideas básicas: a) que el Reglamento Roma I se aplica, como dispone el artículo 1, apartado primero, a las «obligaciones contractuales», por lo que la ley aplicable a las mismas debe determinarse, en principio, conforme a las normas de conflicto contempladas en

\footnotetext{
${ }^{11}$ Véanse los puntos 36 y 37 de las Conclusiones del Abogado General.

12 Entre los motivos esgrimidos por la doctrina para rechazar la calificación global, destaca la falta de previsibilidad y seguridad jurídica para las partes contratantes. Para profundizar sobre el tratamiento de las operaciones contractuales complejas en sede de ley aplicable, véanse J. Carrascosa GonzÁlez y P. Mengozzi, El contrato internacional (Fraccionamiento versus unidad), Madrid, Civitas, 1992, pp. 148-155; M.A. Cebrián SAlvat, "Las operaciones...", op. cit., pp. 358-375; F. Esteban De LA Rosa, La joint venture en el comercio internacional, Granada, Comares, 1999, pp. 86-89.

${ }^{13}$ Véanse F. Esteban De La Rosa, La joint venture..., op. cit., pp. 270-276; A. Hernández Rodríguez, "Los contratos internacionales de construcción «llave en mano»”, Cuadernos de Derecho Transnacional (Marzo 2014), Vol. 6, No 1, pp. 195-199 y 231-232. No obstante, la doctrina valora la posibilidad -teniendo en cuenta el mayor o menor grado de interdependencia entre dichas relaciones jurídicas-, de aplicar a todas o algunas de ellas (según se desprenda del conjunto de circunstancias) la ley que presente vínculos manifiestamente más estrechos. Activando para ello, a modo de ejemplo, la cláusula de excepción prevista en el artículo 4, apartado tercero, del Reglamento Roma I.

${ }^{14}$ D. BuREAU, "L'application du réglement Rome I à un contrat de fiducie ayant pour objet la gestion d'une participation dans une société en commandite et contenant une clause d'electio juris abusive", Rev. crit. DIP, avril-juin 2020, p. 356. En palabras de este autor, "cette questión de délimitation des frontières n'est évidemment pas nouvelle pour les internationalistes, où elle s'exprime classiquement en termes de conflit de catégories".
} 
dicho instrumento normativo ${ }^{15}$; b) que el apartado segundo, letra f), del mencionado precepto excluye expresamente del ámbito de aplicación del Reglamento las «cuestiones pertenecientes al Derecho de sociedades, asociaciones y otras personas jurídicas» ${ }^{16}$.

18. Por todo ello, la delimitación entre las reglas de conflicto en materia de obligaciones contractuales (establecidas en el Reglamento Roma I) y las reglas de conflicto en materia societaria (no armonizadas en el seno de la Unión), exige un riguroso ejercicio de clasificación distributiva en función de las cuestiones sobre las que se esté litigando ${ }^{17}$. En tal sentido se abordan los próximos apartados, en los que -al hilo de ciertas ideas fundamentales, pormenorizadamente ilustradas por la doctrina española especializada- se expone la doctrina sentada por el TJUE en la sentencia que aquí se comenta, poniendo el foco en el tratamiento que recibe este tipo de negocios fiduciarios en Derecho internacional privado europeo.

\section{Alcance del artículo $\left.1.2^{\circ} . f\right)$ del Reglamento Roma I}

19. A modo de contextualización, se ha de partir de la base de que las instituciones europeas han venido mostrando cierta «desconfianza» hacia las normas de conflicto en materia societaria, lo que contrasta con la acentuada importancia del Derecho societario en el marco de la Unión. Esta desconfianza ha llevado a que ni la determinación del Derecho aplicable a la sociedad (lex societatis) ni la concreción de su contenido hayan sido objeto de atención por parte del legislador europeo. Como expone de forma magistral el profesor Arenas al analizar todas estas cuestiones, frente a la ausencia de normas conflictuales de rango institucional -y la inherente falta de previsibilidad y seguridad jurídica en el tráfico-, la jurisprudencia del TJUE ha venido a constituir un «sistema implícito de DIPr de sociedades» ${ }^{18}$. De ahí que la interpretación y aplicación residual de las normas de conflicto de fuente interna en cada EM se vean limitadas, entre otras, por las exigencias derivadas de la libertad de establecimiento de personas jurídicas, contemplada en el art. 54 del TFUE ${ }^{19}$.

20. En relación a dicha ausencia de armonización europea, el Reglamento Roma I excluye expresamente de su ámbito material las cuestiones pertenecientes al Derecho societario [artículo 1, apartado segundo, letra f)]. El alcance de tal exclusión constituye uno de los puntos fundamentales sobre los que se versa la resolución objeto de análisis. Si bien es cierto que tal labor de interpretación es sumamente compleja ${ }^{20}$, se debe partir de la base de que el significado y alcance de la misma no pueden

${ }^{15}$ Artículo 1.1': "El presente Reglamento se aplicará a las obligaciones contractuales en materia civil y mercantil en las situaciones que impliquen un conflicto de leyes".

${ }_{16}$ Artículo 1.2 .f): "Se excluirán del ámbito de aplicación del presente Reglamento: (...) las cuestiones pertenecientes al Derecho de sociedades, asociaciones y otras personas jurídicas, relativas a cuestiones como la constitución, mediante registro o de otro modo, la capacidad jurídica, el funcionamiento interno y la disolución de sociedades, asociaciones y otras personas jurídicas, así como la responsabilidad personal de los socios y administradores como tales con respecto a las obligaciones de la sociedad u otras personas jurídicas".

17 P.A. De Miguel Asensio, “Ámbito de la exclusión del Derecho de sociedades del ámbito de aplicación del Convenio de Roma de 1980 y del Reglamento Roma I: comercialización de fondos de inversión y prestación de servicios en línea (STJ $1^{\text {a }} 3$ octubre 2019. Asunto C-272/18: Verein für Konsumenteninformation)", AEDIPr, t. XIX-XX, 2019-2020, p. 525.

18 R. Arenas García, "El legislador europeo y el DIPr de sociedades”, Revista Española de Derecho Internacional, vol. 69, 2017/1, pp. 49-52, defiende que no hay motivos para tal desconfianza. Tras examinar la necesidad y posibilidades de que el legislador europeo aborde la regulación del DIPr de sociedades, formula una serie de normas de conflicto especiales a tal respecto; $i d$. "Sombras y luces en la jurisprudencia del Tribunal de Justicia de la UE en materia de Derecho internacional privado de sociedades", en C. Esplugues Mota y G. Palao Moreno (eds.), Nuevas fronteras del Derecho de la Unión Europea. Liber amicorum José Luis Iglesias Buhigues, Valencia, Tirant lo Blanch, 2012, pp. 739-759, para un análisis de la jurisprudencia del TJUE en esta materia.

19 R. Arenas García, "El legislador europeo...", op. cit., pp. 49-57 y esp. p.64. Véanse, igualmente, A.L. Calvo Caravaca y J. Carrascosa González (dirs.), Tratado de Derecho internacional privado, Valencia, Tirant lo Blanch, 2020, pp. 2720-2723; F.J. Garcimartín Alférez, Derecho internacional..., op. cit., pp. 339-340.

${ }^{20}$ Examinando desde una perspectiva crítica la dificultad que entraña la determinación del alcance de tal expresión, véase J.C. Fernández Rozas y S. SÁnchez Lorenzo, Derecho Internacional Privado, Cizur Menor (Navarra), Aranzadi, 2020 , p. 641. 
ser establecidos por el Derecho de cada Estado parte. Puesto que este concepto ayuda a definir el ámbito de aplicación de un Reglamento europeo -y que debe garantizarse su aplicación uniforme por todos sus Estados parte-, requiere un significado autónomo ${ }^{21}$, con arreglo al tenor literal de esta disposición, a su génesis y al sistema y los objetivos de este Reglamento ${ }^{22}$.

21. Cabe destacar la exhaustiva labor de interpretación llevada a cabo por el Abogado General en sus conclusiones ${ }^{23}$, en las que atiende a algunas de las técnicas de interpretación más extendidas en el ámbito del DIPr europeo: (i) Haciendo referencia, en primer lugar, a la literalidad de la disposición, sostiene que si bien el art.1.2.f) RRI enumera algunas materias -a modo de calificación ejemplificativacomo la constitución, la capacidad jurídica, el funcionamiento interno y la disolución de las sociedades, así como la responsabilidad personal legal de los socios y administradores con respecto a las obligaciones de la sociedad u otras personas jurídicas, dicha enumeración no es exhaustiva, sino meramente ilustrativa ${ }^{24}$; (ii) Atendiendo, por otro lado, a la génesis de esta exclusión, recuerda que se debe tener en cuenta que la introducción de esta exclusión en el Convenio de Roma respondió, en parte, a la disparidad normativa existente entre los Estados parte en materia societaria ${ }^{25}$; (iii) Por último, en lo que al sistema y objetivos del Reglamento Roma I se refiere, el Abogado General parte de dos ideas relevantes: (a) de un lado, que las sociedades que operan en el contexto internacional están vinculadas con distintos ordenamientos jurídicos, que pueden pretender regularlas; y (b) de otro lado, que en los sistemas jurídicos de los Estados miembros se acepta generalmente que, a fin de garantizar la previsibilidad y la seguridad jurídica -así como en interés de sus acreedores y socios-, determinados aspectos societarios han de regirse de manera uniforme por la denominada lex societatis ${ }^{26}$.

22. Sobre la base del análisis realizado por el Abogado General, el Tribunal de Justicia concluye que la exclusión contemplada en el artículo 1, apartado segundo, letra f), únicamente se refiere a los «aspectos orgánicos de esas sociedades», esto es, a los «actos pertenecientes al Derecho de sociedades», entendiendo por tales todos los actos necesarios para la constitución de una sociedad o que rigen su vida interna o su disolución ${ }^{27}$. Con otras palabras, se excluyen aquellas cuestiones que queden comprendidas en el ámbito de la lex societatis $^{28}$.

${ }^{21}$ A.L. Calvo Caravaca y J. Carrascosa González, Tratado..., op. cit, p. 2736; J. CARRASCOSA GONZÁleZ, La ley aplicable a los contratos internacionales: el Reglamento Roma I, Madrid, Colex, 2009, pp. 92-93; F. J. GARCIMARTín AlFÉREZ, Derecho internacional..., op. cit., pp. 76-78; R. PLENDER, The european contracts..., op. cit., pp. 29-30.

${ }^{22}$ Véase, por analogía, el razonamiento que siguió el TJUE en la STJUE de 14 de noviembre de 2002, Baten (C-271/00, EU:C:2002:656), apartado 42; en la STJUE de 22 de febrero de 1979, Gourdain (C-133/78, EU:C:1979:49), apartado 3, así como en la STJUE de 3 de octubre de 2013, Schneider (C-386/12, EU:C:2013:633), apartado 19.

${ }^{23}$ Puntos 42 a 45 de las conclusiones.

${ }^{24}$ Esta interpretación queda confirmada por el Informe GiulianoLagarde (DO 1980 C 282, p.1), en el que se precisa que esta exclusión se refiere a todos los actos de naturaleza compleja que son necesarios para la constitución de una sociedad o para regir su vida interna o su disolución. Véase la STJUE de 8 de mayo de 2019, Kerr (C25/18, EU:C:2019:376), apartados 33 y 34.

${ }^{25}$ Examinando la diversidad jurídica material y conflictual inherentes al Derecho societario internacional, destacan A.L. CALvo Caravaca y J. Carrascosa GonzÁlez, Tratado..., op. cit., p. 2689 y ss., que comentan hasta seis teorías diferentes al respecto.

${ }^{26}$ Considerandos 6 y 16 del Reglamento.

27 Apartados 35 y 36 de la sentencia.

${ }^{28}$ Como exponen J.C. Fernández Rozas y S. Sánchez Lorenzo, Derecho..., op. cit., pp. 641-642, el Legislador europeo no ha tenido en cuenta la «tendencia contractualista» en esta materia. Si bien se entiende que ciertos aspectos societarios queden excluidos de este Reglamento Roma I por su dimensión institucional, otros deberían quedar incluidos en el ámbito material del instrumento europeo. De esta forma, el Reglamento resultaría aplicable no solo a los contratos celebrados por las sociedades (ej. contratos fiduciarios), sino también las propias obligaciones entre la sociedad y sus socios. En cuanto a la doctrina más contractualista, destaca, entre otros, R. CARO GÁNDARA, La competencia judicial internacional en materia de régimen interno de sociedades en el espacio jurídico europeo, Madrid, Civitas, 1999, esp. pp. 40-71; F. Garcimartín Alférez, "Derecho de sociedades y conflictos de leyes: la determinación de la Lex societatis y su ámbito de aplicación", Cuadernos de derecho judicial, No. 19, 2004, pp. 67-176; id. Derecho de sociedades y conflictos de leyes: una aproximación contractual, Editoriales de Derecho Reunidas. EDERSA, 2002, pp. 117-134. 
No obstante, la ausencia de una normativa europea uniforme en materia societaria ${ }^{29}$ hace que sea sumamente complejo, si no imposible, proporcionar una definición exhaustiva de lo que constituye una «cuestión perteneciente a la lex societatis». Como consecuencia, el Abogado General sostiene se debe analizar caso por caso, atendiendo a los «principios generales que se desprenden de los ordenamientos jurídicos nacionales», cuyas normas de conflicto -además de las sustantivas- suelen enumerar las cuestiones pretendidas en dicho ámbito ${ }^{30}$. Cabe intuir la dificultad que ello puede suponer, pues las divergencias presentes en dichos sistemas jurídicos y la forma en que, consecuentemente, cada uno de ellos aplique el Reglamento europeo, menoscabarían claramente el principio de uniformidad de soluciones entre los Estados miembros del Reglamento. Una misma realidad jurídica puede ser incluida o excluida del ámbito material del mismo dependiendo del Estado parte en que se esté dirimiendo la misma. Como expone el Abogado General, "ante estas divergencias, es sin duda conveniente centrarse en el "núcleo duro» de cuestiones generalmente aceptadas en estos Estados, con el fin de preservar el objetivo de previsibilidad y seguridad jurídica en cuanto al Derecho aplicable a una sociedad perseguido por el artículo 1, apartado 2, letra f), del Reglamento Roma I. En este contexto, los estatutos de una sociedad, en la medida en que regulan las cuestiones relativas a su funcionamiento interno, como el alcance y el ejercicio de los derechos políticos (entre ellos el derecho a voto) y los derechos pecuniarios (entre ellos el derecho a dividendos) que se derivan de la condición de socio, están comprendidos en la exclusión prevista en esa disposición" ${ }^{\prime \prime 1}$.

\section{Aspectos societarios presentes en los fondos de inversión inmobiliaria controvertidos}

23. Atendiendo particularmente a los fondos de inversión inmobiliaria objeto del litigio principal, el Tribunal de Justicia declara que la condición o no de socios de los fiduciantes, los eventuales derechos y obligaciones que los fiduciantes tienen frente a las sociedades comanditarias, las eventuales obligaciones de los fiduciantes frente a terceros acreedores de la sociedad, así como los estatutos de la sociedad fiduciaria (en la medida en que regulan el funcionamiento interno de la misma, el alcance y ejercicio del derecho a voto y del derecho de los fiduciantes a los dividendos) son cuestiones que se rigen por el Derecho de sociedades y, por tanto, quedan excluidas del ámbito de aplicación material del Reglamento ${ }^{32}$.

24. Aunque los negocios fiduciarios puedan plantear cuestiones pertenecientes al Derecho de sociedades, como las expuestas en el párrafo anterior, no ocurre lo mismo con los contratos subyacentes a tales operaciones ${ }^{33}$. Como ha señalado el Abogado General y reafirmado el Tribunal de Justicia en su sentencia, la mera circunstancia de que un contrato fiduciario tenga vínculos con cuestiones societarias, no tiene por efecto excluir del ámbito material del Reglamento Roma I las obligaciones que tienen su origen en dicho contrato ${ }^{34}$.

\footnotetext{
29 Véase supra apartado 19.

${ }^{30}$ En el ordenamiento jurídico español, el art. $9.11^{\circ} \mathrm{Cc}$ hace referencia expresa a la capacidad, la constitución, la representación, el funcionamiento, la transformación, la disolución y la extinción de las personas jurídicas. En opinión de F. GARCIMARTíN Alférez, Derecho internacional..., op. cit., p.336, esta norma de conflicto se refiere al "estatuto personal" de las personas jurídicas en su conjunto, esto es, tanto a los aspectos internos como a los aspectos externos de la sociedad.

31 El Abogado General cita como obra de referencia a C. GernerBeuerle, F. Mucciarelli, E. Schuster y M. Siems, The Private International Law of Companies in Europe, Beck, Hart and Nomos, 2019, pp. 47 a 127. Merecen especial atención, en este contexto, las exhaustivas normas de conflicto propuestas por R. ARENAS GARCíA, "El legislador europeo...”, op. cit., pp.64-72.

32 Véanse, especialmente, el apartado 39 de la sentencia y el punto 48 de las conclusiones del Abogado General. En tal sentido, P.A. De Miguel Asensio, “Ámbito de la exclusión...”, op. cit., p. 525.

${ }^{33}$ En tal sentido, el Tribunal de Justicia ya declaró, en la STJUE de 7 de abril de 2016, KAFinanz (C-483/14, EU:C:2016:205, apartados 52 a 58), que, tras la absorción de una sociedad transfronteriza, la ley aplicable a la interpretación, el cumplimiento y la extinción de las obligaciones que generaban los contratos seguía siendo la ley que regía los mismos antes de su fusión.

${ }^{34}$ Apartado 37 de la sentencia.
} 
25. Por lo tanto, no deben confundirse las cuestiones societarias (excluidas del ámbito material del instrumento europeo) con las cuestiones de carácter contractual, que pertenecen al ámbito de aplicación de la lex contractus y, por ende, del citado Reglamento ${ }^{35}$.

La acción de cesación entablada por VKI versaba sobre el carácter abusivo y, por ende, la licitud de determinadas cláusulas de los contratos fiduciarios controvertidos, las cuales se refieren a cuestiones como el alcance de la responsabilidad de TVP en su condición de fiduciaria, los plazos de prescripción y de caducidad de los que dispone el inversor para ejercitar una acción de indemnización contra la sociedad fiduciaria, el lugar de prestación de los servicios fiduciarios y la ley aplicable al contrato fiduciario. Asimismo, en términos de «relaciones internas», las cláusulas contractuales controvertidas tienen por objeto regular las relaciones entre fiduciante y fiduciario. Obligaciones existentes entre ambos en virtud del contrato fiduciario. Incluso cuando dicho contrato reproduzca los derechos y obligaciones establecidos en contratos societarios, solo serán oponibles entre las partes en la medida en que el contrato fiduciario contemple tal posibilidad ${ }^{36}$.

Todas estas cuestiones pertenecen al ámbito de la lex contractus y, por ende, del Reglamento Roma I. De ahí que el Tribunal de Justicia concluya que, independientemente del posible vínculo que la operación pueda tener con el Derecho societario, las obligaciones contractuales que tienen su origen en contratos fiduciarios no están comprendidas en la exclusión prevista en el artículo 1, apartado segundo, letra f) del Reglamento ${ }^{37}$.

\section{Fondos de inversión inmobiliaria y régimen de protección de consumidores del Reglamento Roma I}

\section{Los contratos fiduciarios y el artículo 6.1 del Reglamento Roma I}

26. Una vez constatado que la ley aplicable a las obligaciones que tienen su origen en contratos fiduciarios será determinada de conformidad con las normas de conflicto de leyes previstas en el Reglamento Roma I en este apartado, se dará un paso más. Se tratará de determinar si los contratos fiduciarios que tienen por objeto la administración de participaciones en fondos de inversión inmobiliaria son «contratos de consumo» a los efectos del citado Reglamento y, posteriormente, si resulta aplicable el régimen especial de protección de los consumidores contemplado en el artículo 6 del texto ${ }^{38}$.

27. Como ha manifestado el Tribunal de Justicia en numerosas ocasiones, si bien los conceptos utilizados en el Reglamento Roma I y, particularmente, los que figuran en el mencionado precepto deben ser interpretados de forma autónoma, procede tener en cuenta el concepto de «consumidor» contenido en otras normas europeas (como el Reglamento Bruselas I bis). Todo ello a fin de garantizar el cumplimiento de los objetivos perseguidos por el legislador europeo y la coherencia del Derecho de

\footnotetext{
35 Ámbito de la ley aplicable, artículo 12 del Reglamento Roma I: "1. La ley aplicable al contrato en virtud del presente Reglamento regirá en particular: a) su interpretación; b) el cumplimiento de las obligaciones que genere; c) dentro de los limites de los poderes conferidos al tribunal por su Derecho procesal, las consecuencias de un incumplimiento total o parcial de estas obligaciones, incluida la evaluación del daño en la medida en que la gobiernen normas jurídicas; d) los diversos modos de extinción de las obligaciones, así como la prescripción y la caducidad basadas en la expiración de un plazo; e) las consecuencias de la nulidad del contrato. 2. En lo que se refiere a las modalidades del cumplimiento y a las medidas que se deben tomar en caso de cumplimiento defectuoso, se tendrá en cuenta la ley del país donde tenga lugar el cumplimiento".

${ }^{36}$ Véanse los apartados 39 a 41 de la sentencia y puntos 49 a 59 de las Conclusiones del Abogado General.

37 P.A. De Miguel Asensio, “Ámbito de la exclusión...”, op. cit., pp. 525-526.

${ }^{38}$ Considerando 23 RRI: "En cuanto a los contratos celebrados con partes consideradas más débiles, es conveniente protegerlas por medio de normas de conflicto de leyes más favorables a sus intereses que las normas generales". Se parte, pues, de la idea de desigualdad entre las partes, derivada de la experiencia, conocimiento y recursos profesionales de los que dispone una de ellas frente a la otra. Véase D. CARrizo Aguado, "Observación jurisprudencial relativa a la ley aplicable a la compraventa de bienes inmuebles radicados en el extranjero. Estudio de caso a partir de la SAP de Murcia, num. 98/2020", Cuadernos de Derecho Transnacional, vol. 13, no. 1, marzo 2021, pp. 771-773; J.M. DE DIOS MARCER, “Autonomía...”, op. cit., p. 6.
} 
la UE (considerando 7 RRI) ${ }^{39}$. No obstante, esto debe ser matizado, pues, aunque "se ha de velar por el mantenimiento de la uniformidad de los regímenes jurídicos relativos a las reglas de conflicto de leyes y a la determinación de la competencia internacional en materia de contratos con consumidores", el artículo 17, apartado primero, del Reglamento Bruselas I bis y el artículo 6, apartado primero, del Reglamento Roma I no deben interpretarse de forma idéntica. Téngase en cuenta que tales Reglamentos no tienen el mismo objeto, "por cuanto el primero regula las cuestiones de procedimiento, mientras que el segundo trata de la problemática de los conflictos de leyes con el fin de determinar el Derecho material aplicable"40.

28. Como sabemos, para poder aplicar el artículo 6 del Reglamento Roma I se deben cumplir ciertas condiciones cumulativas (subjetivas, materiales y espaciales). Se debe constatar, en primer lugar, que el contrato haya sido celebrado entre un «consumidor» y un «profesional». Por otro lado, que el profesional haya internacionalizado su negocio. Y, además, que no se trate de uno de los supuestos excluidos en el apartado cuarto de dicho precepto ${ }^{41}$.

29. Según reiterada jurisprudencia del TJUE, el concepto de «consumidor» debe interpretarse de forma restrictiva, y "en relación con la posición de esta persona en un contrato determinado y con la naturaleza y la finalidad de éste, y no con la situación subjetiva de dicha persona"42. Cabe destacar que, tal y como ha afirmado el Tribunal de Justicia en numerosas sentencias, este concepto se define por oposición al de «operador económico», de modo que solo serán considerados consumidores aquellas personas físicas que contraten para satisfacer las propias necesidades de su consumo privado, esto es, para un uso que pueda considerarse ajeno a su actividad comercial o profesional (consumidor final privado ${ }^{43}$.

Como sabemos, en el litigio principal del presente asunto, los inversores interesados en participar en los fondos de inversión inmobiliaria -comercializados por la sociedad fiduciaria (TVP)- remitían a ésta una declaración de adhesión en forma de oferta de celebración de un contrato fiduciario, e ingresaban el importe correspondiente a la participación en la cuenta fiduciaria del fondo elegido (abierta a nombre de la sociedad fiduciaria). La condición o no de consumidores de estos inversores estará supeditada, por tanto, al hecho de que actúen con fines que puedan considerarse ajenos a su actividad profesional o comercial ${ }^{44}$. Esta circunstancia se dará en numerosas ocasiones, pero, en muchas otras, será sumamente complejo determinar si se trata realmente de consumidores privados. Para ello, "no se tendrán en cuenta los conocimientos y la información que el inversor de que se trate dispone realmente, o la especialización que el mismo pueda alcanzar en el ámbito del que forman parte dichos servicios"45. Por todo ello se

39 STJUE de 2 de mayo de 2019, Pillar Securitisation (C-694/17, EU:C:2019:345), apartado 34 y jurisprudencia citada.

${ }^{40}$ STJUE de 3 de octubre de 2019, Petruchová (C-208/18, EU:C:2019:825), apartado 33. En tal sentido, S. SÁnCHEZ LoRENzo, "El principio de coherencia en el Derecho internacional privado europeo", REDI, Vol. 70, No 2, 2018, pp. 17-47.

${ }^{41}$ C.M. CaAmiña Domínguez, "El consumidor frente al profesional en entornos digitales. Tribunales competentes y ley aplicable", Cuadernos de Derecho Transnacional, vol. 12, núm. 2, 2020, pp. 175-176; A.L. Calvo CaravaCa y J. CARrascosa GonzÁlez, Tratado..., op. cit., pp. 3322-3330; J.M. De Dios MARCER, “Autonomía de la voluntad, protección del consumidor y Derecho aplicable a los contratos de consumo en el Reglamento 593/2008: Sentencia del Tribunal de Justicia de 3 de octubre de 2019, Asunto C-272/18”, La Ley Unión Europea, febrero 2020, №78, pp. 5-6.

${ }^{42}$ Se pronuncian sobre este punto, entre otras, la STJUE de 14 de febrero de 2019, Milivojević (C-630/17, EU:C:2019:123), apartado 87; y la STJUE de 25 de enero de 2018, Schrems (C-498/16, EU:C:2018:37), apartado 29.

${ }^{43}$ Pronunciándose sobre este particular, destacan la STJUE de 10 de diciembre de 2020,AB BB (C-774/19, EU:C:2020:1015), apartados 29 a 31; la STJUE de 14 de marzo de 2013, Cèská spořitelna (C-419/11, EU:C:2013:165), apartado 32; la STJUE de 19 de enero de 1993, Shearson Lehman Hutton (C-89/91, EU:C:1993:15), apartado 23; STJUE de 20 de enero de 2005, Gruber (C464/01, EU:C:2005:32), apartados 36 y 37. Véase A.L. Calvo CaravacA, "Consumer contracts in the European Court of Justice case law. Latest trends", Cuadernos de Derecho Transnacional, vol. 12, núm. 1, 2020, pp. 93-94.

${ }^{44}$ D. CARrizo Aguado, "Observación jurisprudencial...", op. cit., p. 772, hace una interesante reflexión al respecto: "con la llegada del asunto Petruchovà se aprecia una formidable calificacion de consumidor a favor de los inversionistas; el juzgador europeo estima que, ni el volumen del dinero invertido, ni los riegos y p6rdidas alcanzadas, ni tan siquiera la pericia del inversor, van a demoler los beneficios conferidos a los clientes inversionistas en las normas de Derecho internacional privado europeas".

${ }^{45}$ Véase la sentencia, antes citada, AB BB, apartados 39 y 40; Petruchová, apartado 56; y de 3 de septiembre de 2015, Costea (C110/14, EU:C:2015:538), apartado 21. En tal sentido, J.C. Fernández Rozas y S. SÁnchez Lorenzo, Derecho..., op. cit., pp. 677-682. 
concluye que los contratos fiduciarios controvertidos únicamente serán considerados «contratos de consumo» a los efectos del Reglamento Roma I cuando el «profesional» (en este caso, la sociedad fiduciaria TVP) contrate con inversores/fiduciantes que tengan la condición de «consumidores»: personas físicas que celebren estos contratos para un propósito que puede considerarse ajeno a tal actividad ${ }^{46}$. De modo que en los supuestos en los que los inversores sean personas jurídicas o no contraten con fines privados, no resultará aplicable el régimen de protección de consumidores previsto en el art. $6^{47}$.

30. El otro contratante debe ser un «profesional», entendiendo como tal aquella persona que actúa en ejercicio de su actividad comercial ${ }^{48}$. En este asunto, se observa que TVP (como sociedad fiduciaria y socia comanditaria fundacional) sí tiene condición de profesional, pues ofrece a los fiduciantes la prestación de un servicio fiduciario. Asume la participación comanditaria por cuenta del inversor y la administra a título fiduciario, remitiéndole los dividendos, así como el resto de ventajas patrimoniales. Por estos servicios, cobra una comisión global del $0.3 \%$ de la aportación del inversor ${ }^{49}$.

31. En cuanto al ámbito espacial de la norma, debe recordarse que el Reglamento Roma I no protege a todos los consumidores, sino solamente a los denominados «consumidores pasivos», esto es, a aquellos que no hayan tenido una actitud «activa» en la celebración del contrato ${ }^{50}$. La operación ha de localizarse, por tanto, en el Estado de la residencia habitual del consumidor. Se pueden distinguir dos situaciones en este sentido: $1^{\circ}$ ) que el profesional ejerza sus actividades comerciales o profesionales en el país donde el consumidor tenga su residencia habitual; $2^{\circ}$ ) o que por cualquier medio dirija estas actividades a ese país o a distintos países, incluido ese país ${ }^{51}$.

En el asunto que nos ocupa, la celebración de los contratos fiduciarios se llevaba a cabo en Austria, donde los consumidores austriacos realizaron los actos necesarios para la celebración del negocio, al tiempo que la otra parte contratante recibió en el mismo lugar el encargo. Por todo ello, se deduce que la sociedad fiduciaria dirigió efectivamente su actividad al mercado austriaco. En principio, estos contratos fiduciarios cumplen los requisitos previstos en el apartado primero del art.6 Reglamento Roma I, pero aún resta comprobar si constituyen uno de los supuestos excluidos expresamente en virtud del apartado cuarto del citado precepto.

\section{Exclusión prevista en el art. 6.4.a) del Reglamento Roma I: servicio fiduciario prestado "exclu- sivamente" en un Estado diferente al de la residencia habitual del consumidor}

32. El art. 6 Reglamento Roma I excluye expresamente, en su apartado 4, determinados contratos de su ámbito de aplicación. Particularmente, la letra a) establece que las normas de protección en

\footnotetext{
46 Apartado 62 de las conclusiones del Abogado General.

${ }^{47}$ En cualquier caso, resulta destacable que en este asunto ni el AG ni el TJUE se cuestionen tales extremos. Se limitan a hacer suya la calificación que realizó el órgano remitente en tal sentido. Véase J.M. DE Dios MarCER, “Autonomía...”, op. cit., p. 6.

${ }^{48}$ No se exige en este punto que tal actividad comercial esté inscrita en ningún registro. A.L. CALvo Caravaca y J. CARRASCosa GonzÁlez, Tratado..., op. cit., pp. 3297-3299.

49 Apartado 23 de la sentencia.

50 Analizando exhaustivamente este requisito, D. Carrizo Aguado, "Examen detallado de la exclusión del Derecho societario en el Reglamento Roma I al hilo del Asunto verein für konsumenteninformation: Fortaleza legal hacia el consumidor inversor", Cuadernos de Derecho Transnacional, vol. 12, n² 2, octubre 2020, pp. 959-965.

${ }^{51}$ A fin de interpretar el concepto de «actividades dirigidas» en el ámbito del comercio electrónico, merecen especial atención las pautas contempladas en el considerando 24 del Reglamento Roma I: (i) «no basta que una empresa dirija sus actividades hacia el Estado miembro del domicilio del consumidor, o hacia varios Estados miembros entre los que se encuentre este último, sino que además debe haberse celebrado un contrato en el marco de tales actividades»; (ii) «el mero hecho de que un sitio Internet sea accesible no basta para que el artículo 15 resulte aplicable, aunque se dé el hecho de que dicho sitio invite a la celebración de contratos a distancia y que se haya celebrado efectivamente uno de estos contratos a distancia, por el medio que fuere. A este respecto, la lengua o la divisa utilizada por un sitio Internet no constituye un elemento pertinente». En tal sentido, A.L. Calvo Caravaca y J. Carrascosa González, Tratado..., op. cit., pp. 3228-3330; D. Carrizo Aguado, "Examen detallado...”, op. cit., p. 961; J.C. Fernández Rozas y S. SÁnchez Lorenzo, Derecho..., op. cit., pp. 685-686; F. Garcimartín Alférez, Derecho internacional..., op. cit., p. 370-372.
} 
materia de contratos de consumo no se aplicarán a "los contratos de prestación de servicios cuando los servicios deban prestarse al consumidor, exclusivamente, en un país distinto de aquel en que el mismo tenga su residencia habitual" 52 . Como señala el Informe Giuliano-Lagarde, esta exclusión está justificada por el hecho de que, en tales circunstancias, el consumidor no puede esperar razonablemente que se aplique la legislación de su Estado de origen ${ }^{53}$. Además, el profesional, que presta servicios a consumidores que proceden de todo el mundo, tendría que informarse sobre una infinidad de Leyes estatales distintas, lo que dispararía los costes de esos servicios ${ }^{54}$. Del tenor literal de dicha exclusión se desprenden dos requisitos cumulativos: por una parte, que se trate de un "contrato de prestación de servicios" (condición material); y, de otra, que "los servicios deban prestarse al consumidor, exclusivamente, en un país distinto de aquel en que el mismo tenga su residencia habitual" (condición territorial).

33. En relación a qué se entiende por «contrato de prestación de servicios», cabe destacar que este concepto debe ser objeto de una interpretación uniforme, en el sentido de que debe entenderse del mismo modo que el que figura en el artículo 4.1.b) del Reglamento Roma I y en el actual artículo 7.1.b) del Reglamento Bruselas I bis ${ }^{55}$. De la jurisprudencia del Tribunal de Justicia se desprende que el concepto «prestación de servicios» debe interpretarse en un sentido muy amplio. Implica, en términos generales, que la parte que los presta lleve a cabo una determinada actividad a cambio de una remuneración ${ }^{56}$.

En este contexto, ha de recordarse que los negocios fiduciarios de administración son operaciones complejas consistentes en la transmisión de la propiedad de un bien con el fin de que el fiduciario lo administre -en los términos y plazos convenidos- y lo retransmita al fiduciante una vez finalizada la gestión acordada. Se asimilan, en cierto modo, a otras figuras que comportan distintas prestaciones y transmisión de la propiedad de ciertos bienes al mismo tiempo, como los contratos de franquicia, de distribución, de restauración, etc ${ }^{57}$. Un sector doctrinal afirma que debe calificarse atendiendo a la finalidad del negocio, no en función de la obligación principal del mismo: si la finalidad económica del negocio es la prestación del servicio y no la transmisión de la propiedad, este debe calificarse como contrato de prestación de servicios. Por el contrario, si el fin del contrato es la transmisión de la propiedad de una cosa en sí, el contrato no será una prestación de servicio ${ }^{58}$.

${ }^{52}$ Coincide con la excepción prevista en el artículo 5.4.a) del Convenio de Roma.

${ }^{53}$ En lo que respecta al contexto en el que se inscribe el art. 6.4.a) Reglamento Roma I, esta disposición debe interpretarse de forma estricta, ya que establece una excepción al objetivo de protección que, con carácter general, persigue dicho artículo.

54 A.L. Calvo Caravaca y J. Carrascosa González, Tratado..., op. cit., p. 3323.

${ }^{55}$ Considerando 17 del Reglamento Roma I: “(...) los conceptos de «prestación de servicios» y de «venta de mercaderías» deben interpretarse del mismo modo que al aplicar el artículo 5 del Reglamento (CE) no 44/2001, en cuanto la venta de mercaderías y la prestación de servicios están cubiertos por dicho Reglamento (...)”. Como sabemos, la referencia al Reglamento Bruselas I debe entenderse hecha al Reglamento Bruselas I bis.

56 A.L. Calvo Caravaca y J. Carrascosa González, Tratado..., op. cit., pp. 2825-2829 y 2950-2952. Partiendo de criterios económicos, estos autores definen el contrato de prestación de servicios como "aquel contrato que tiene como objetivo principal la realización, a cambio de una remuneración, de una actividad que consiste en dar, hacer o no hacer una cosa, a título oneroso, gratuito o lucrativo, y no la transmisión de la propiedad de una cosa ni tampoco la mera abstención o el mero «dejar hacer» por parte de un contratante en favor del otro". Destaca, en este sentido, la STJUE de 8 de mayo de 2019, Kerr (C-25/18, EU:C:2019:376), apartados 36 a 41. Es importante recordar en este punto que, tal y como expresa el TJUE en la sentencia de 23 de abril de 2009, Falco Privatstiftung (C-533/07, EU:C:2009:257), apartados 34 y 35, el concepto de «servicios» que figura en el Reglamento Bruselas I bis no se corresponde necesariamente con el que ofrecen los artículos 56 y ss. del TFUE en materia de libre prestación de servicios. Mientras que en el primer caso se exige una interpretación restrictiva (por tratarse de foros especiales que excepcionan el principio general del domicilio del demandado), sí se justifica una interpretación más amplia en el ámbito de las libertades fundamentales del Mercado Interior, a fin de favorecer la libre circulación de mercancías, de capitales o de personas en la Unión (J.M. De Dios Marcer, “Autonomía...”, op. cit., nota 22).

57 Sobre el carácter complejo de los contratos de franquicia y de distribución, la regulación específica contemplada en las letras e) y f) del art. 4.1 Reglamento Roma I quedan justificadas, en opinión de numerosos autores, por la dificultad que entrañaría la identificación de la prestación característica, a quién correspondería la misma, etc. Véase P.A. DE MiguEL AsEnSio, "Contratación comercial internacional", en J.C. Fernández Rozas, R. Arenas García y P.A. De Miguel Asensio, Derecho de los negocios internacionales, sexta edición, Madrid, Iustel, 2020, p. 368.

58 A.L. Calvo Caravaca y J. Carrascosa GonzÁlez, Litigación internacional en la Unión Europea I. Competencia judicial $y$ validez de resoluciones en materia civil y mercantil en la Unión Europea. Comentario al Reglamento Bruselas I Bis, Cizur Menor (Navarra), Aranzadi, 2017, pp. 161-164; id. Tratado..., op. cit., pp. 2828-2829 y 2951-2952; P.A. De Miguel Asensio, "Contratación comercial...", op. cit., pp. 368-373. 
En este asunto, el Tribunal de Justicia considera que los contratos fiduciarios controvertidos tienen por objeto una prestación de servicios en el sentido del artículo 6, apartado cuarto, letra a) del Reglamento Roma I, pues la sociedad TVP ofrece servicios de gestión fiduciaria consistentes en la administración de las participaciones de los inversores, a cambio de una remuneración del $0.3 \%$ de la aportación de estos ${ }^{59}$.

34. La determinación del lugar de prestación de los servicios, en el sentido del artículo 6.4.a) del Reglamento (en el que se excluye la aplicación del régimen de protección "cuando servicios deban prestarse al consumidor, exclusivamente, en un país distinto de aquel en que el mismo tenga su residencia habitual" $)^{60}$, es una de las aportaciones más relevantes y actuales de este asunto, pues se trata de la primera ocasión en la que el Tribunal de Justicia se pronuncia sobre este particular en el ámbito del «comercio electrónico directo» ${ }^{61}$.

Al determinar el lugar en que "deban prestarse" los servicios al consumidor, procede atender, desde un punto de vista fáctico, a la naturaleza de los servicios de que se trate ${ }^{62}$. En opinión del Abogado General, "si bien una eventual cláusula de designación del lugar de cumplimiento de las obligaciones contractuales puede resultar indicativa a este respecto, no es en absoluto determinante. La expresión «deban prestarse» no hace referencia, como sostiene TVP, al lugar en el que deban cumplirse esas obligaciones conforme a lo estipulado en el contrato. Como afirma VKI, en realidad es preciso comprobar si de la propia naturaleza de los servicios pactados resulta que estos solo pueden prestarse fuera del país en que el consumidor tiene su residencia habitual"63.

Lo que se debe comprobar es, por tanto, si de la propia naturaleza de los servicios pactados resulta que estos solo pueden prestarse fuera del país en que el consumidor tiene su residencia habitual, de modo que este deba desplazarse a otro país para «recibir» la totalidad de las prestaciones del contrato, donde se ejecuta íntegramente el mismo ${ }^{64}$. La mera circunstancia de que el profesional haya dirigido su actividad al país de la residencia habitual del consumidor no excluye, en sí mismo,

59 Apartado 47 de la sentencia: "En el caso de autos, debe señalarse que, en virtud de un contrato fiduciario como los controvertidos en el litigio principal, la fiduciaria ejerce una actividad consistente en la administración del bien objeto del contrato fiduciario, a cambio de una remuneración. Por consiguiente, debe considerarse que tal contrato tiene por objeto una prestación de servicios en el sentido del artículo 5, apartado 4, letra b), del Convenio de Roma y del artículo 6, apartado 4, letra a), del Reglamento Roma I'.

60 En cuanto al objetivo que persigue esta exclusión, el Informe Giuliano-Lagarde (pp. 24 y 25) explicaba que en el supuesto de contratos relativos a prestaciones de servicios que se prestan exclusivamente fuera del Estado de residencia del consumidor, este no puede esperar razonablemente que se aplique la ley de su Estado de origen. En este caso, el contrato presenta vínculos más estrechos con el Estado en que tiene su residencia habitual la otra parte contratante, incluso si esta ha realizado alguno de los actos descritos en el Estado en que tiene su residencia habitual. Además, debe tenerse en cuenta que la exclusión se mantuvo en el Reglamento Roma I porque se temía que la sobreprotección del consumidor tuviera demasiado impacto en las pequeñas y medianas empresas. Criticando esta exclusión, véase P. LAGARDE, "Remarques sur la proposition de règlement de la Commission européenne sur la loi applicable aux obligations contractuelles (Rome I)", Rev. Crit. DIP, 2006, p. 341.

61 Analizando la importancia que reviste la interpretación realizada por el Tribunal de Justicia de esta exclusión, en relación con el comercio electrónico, destaca P.A. De Miguel Asensio, “Ámbito de la exclusión...”, op. cit., pp. 525-526; id. P.A. De Miguel AsEnsio, "Contratación comercial...", op. cit., p. 389. Este autor señala que esta interpretación es restrictiva, en el sentido en que la exclusión no abarca los contratos de prestación transfronteriza de servicios a distancia en los que el consumidor permanece en el país de su residencia habitual, como es frecuente en el caso de los servicios prestados en línea.

62 Como expresan algunos autores, el lugar de prestación del servicio es un «dato de hecho», no un «dato jurídico». Véase A.L. Calvo Caravaca y J. Carrascosa González, Tratado..., op. cit., p. 2829.

63 Apartado 76 de sus conclusiones. En este contexto, no procede aplicar por analogía la jurisprudencia del Tribunal de Justicia relativa al art. 7.1.b) del Reglamento Bruselas I bis, pues atender casi exclusivamente a las estipulaciones del contrato resultaría inapropiado en el marco del art. 6.4.a) del RRI, puesto que el objetivo de protección que persigue aboga a favor de una interpretación que no dependa del modo en que está redactado dicho contrato. El TJUE estima que, incluso si las partes no han pactado en el contrato cuál es el concreto lugar de prestación del servicio, debe tenerse presente el lugar donde el prestador del servicio «ha desarrollado efectivamente, de manera preponderante, sus actividades en cumplimiento del contrato, siempre que la prestación de los servicios en el lugar en cuestión no sea contraria a la voluntad de las partes según resulte de lo acordado entre ellas» (STJUE de 10 de septiembre de 2015, Ferho (C-47/14, EU:C:2015:574), apartado 64).

64 A.L. Calvo Caravaca y J. Carrascosa González, Tratado..., op. cit., p. 3324. 
la aplicación del art. 6.4 del Reglamento Roma I. De lo contrario, esta disposición quedaría privada de todo efecto útil ${ }^{65}$.

Por todo ello se llega a la conclusión de los contratos fiduciarios controvertidos en el litigio principal no están excluidos del ámbito de protección del artículo 6, pues los servicios fiduciarios no se han prestado exclusivamente en un país distinto de aquel en que el consumidor/inversor tiene su residencia habitual (Austria) ${ }^{66}$. Efectivamente, "el hecho de que las cantidades correspondientes a las participaciones fueran ingresadas por los consumidores austriacos en cuentas fiduciarias en Austria, de que TVP transfiriera a cuentas austriacas los pagos de dividendos y las demás ventajas pecuniarias a las que tienen derecho, de que esta sociedad cumpliera con sus obligaciones de información derivadas del contrato fiduciario enviándoles informes sobre la actividad de los fondos en Austria y de que disponga de un sitio de Internet para esos consumidores, en el que estos pueden consultar información y votar, subraya que esos consumidores reciben el resultado de los servicios prestados por TVP en su país de residencia habitual'"67.

\section{Licitud de las cláusulas de elección de ley insertas en los contratos fiduciarios celebrados con consumidores}

35. En principio, los contratos de consumo se rigen por la ley del país de la residencia habitual del consumidor (regla general prevista en el artículo 6, apartado primero, del Reglamento). Puesto que en el asunto principal los consumidores residen en Austria, la ley aplicable sería, en principio, el Derecho austriaco. No obstante, ha de recordarse que los contratos fiduciarios controvertidos contienen una cláusula de elección de ley en favor del Derecho alemán (Derecho del domicilio social de TVP) ${ }^{68}$.

36. Si bien es cierto que se permite, en principio, a las partes elegir la ley aplicable al contrato, tal posibilidad está condicionada a que dicha elección no acarree para el consumidor la pérdida de la protección que le proporcionen aquellas disposiciones que no puedan excluirse mediante acuerdo en virtud de la ley del país en que el consumidor tenga su residencia habitual ${ }^{69}$. Se refiere a las «normas imperativas», esto es, a aquellas que no son disponibles para las partes contratantes. El TJUE ha indicado, a este respecto, que las disposiciones legales que regulan las cláusulas abusivas y que desarrollan la Directiva 93/13/ $\mathrm{CEE}^{70}$ constituyen normas imperativas cubiertas por el art. 6.2 del Reglamento Roma I.

37. Una cláusula de elección de ley aplicable predispuesta por el profesional puede resultar «abusiva» y por tanto nula. La ley aplicable a la apreciación de una cláusula contractual concreta como

\footnotetext{
${ }^{65}$ Apartado 76 de las conclusiones. Analizando desde una perspectiva crítica si los consumidores pueden suscribir, mediante su adhesión a un contrato, el lugar de prestación de los servicios, véase J.M. DE Dios MARCER, “Autonomía...op.cit., pp. 7-10.

${ }^{66}$ Véase D. Bureau, "L'application...", op.cit, p. 359. Es muy interesante, a mi parecer, la frase con la que este autor concluye su comentario a esta sentencia: "L'originalité provient plutôt ici de l'inexprimé: ce n'est en effet qu'en filigrane que se laisse percevoir -assez nettement tout de même- une interpéetation purement téléologique, substantiellement orientée vers la protection du consommatuer. Une forme de conséquentialisme consumériste, en quelque sorte...".

${ }^{67}$ Apartado 81 de las conclusiones. Véase, en este sentido, A.L. Calvo Caravaca y J. Carrascosa González, Tratado..., op. cit., pp. 3323-3324.

${ }^{68}$ Analizando la tendencia favorable a la autonomía de la voluntad conflictual en el ámbito de la contratación internacional, véanse D. Carrizo Aguado, “Observación jurisprudencial...”, op. cit., pp. 769-771; P.A. De Miguel Asensio, "Contratación comercial...", op. cit., pp. 359-364.

${ }^{69}$ Los profesionales suelen incluir en los contratos que firman con los consumidores unas cláusulas en cuya virtud se aplica un Derecho estatal concreto, que con frecuencia es el Derecho del país donde está establecida la sociedad. Analizando la necesidad de proteger al consumidor frente a «imposiciones de Ley», véase A.L. Calvo Caravaca y J. CARrascosa GonzáLez, Tratado..., op. cit., pp. 3330-3332. Examinando el deber de transparencia de las empresas como «criterio directo de abusividad de la cláusula concernida», véase D. CARRIzo AGUADO, "Inmersión del consumidor transfronterizo en la contratación electrónica: una visión desde el derecho privado europeo", en A. Salinas De Frías y E.J. Martínez Pérez (dirs.), A. SÁnchez Frías y F. PEÑa Díaz (coords.), La Unión Europea y la protección de los derechos fundamentales, Valencia, Tirant lo Blanch, 2018, pp. 163-176.

${ }^{70}$ Directiva 93/13/CEE del Consejo, de 5 de abril de 1993, sobre las cláusulas abusivas en los contratos celebrados con consumidores (DOUE L 1993 80526).
} 
abusiva o no «debe determinarse siempre con arreglo al Reglamento Roma I, esto es, conforme a la Ley del país de domicilio del consumidor (art. 6.2). Si éste reside habitualmente en un Estado miembro de la UE, la Directiva 93/13/CEE sobre cláusulas abusivas es aplicable. El carácter abusivo de una cláusula sólo puede ser declarado tras un examen caso por caso que tenga en cuenta todas las circunstancias pertinentes, incluida la naturaleza de los bienes o de los servicios que sean objeto del contrato (art. 4.1 Directiva 93/13/CEE).

Siguiendo el pormenorizado estudio realizado por los profesores Calvo Caravaca y Carrascosa González, «serán abusivas las cláusulas contractuales cuando: (a) no se hayan negociado individualmente, causando un desequilibrio importante entre los derechos y las obligaciones de las partes; (b) cuando hayan sido redactadas previamente por el profesional (en particular en el caso de los contratos de adhesión), de modo que el consumidor no haya podido influir sobre su contenido; (c) no hayan sido redactadas de forma clara y comprensible, informando al consumidor de que son aplicables las normas imperativas del país de su residencia habitual, de conformidad con el art. $6.2 \mathrm{RRI}\rangle^{71}$.

38. Por todo ello, el Tribunal de Justicia reproduce en general la respuesta dada en la sentencia Amazon $^{72}$, en la que establece las reglas de juego entre la Directiva 93/13/CEE y el Reglamento Roma I en materia de contractos internacionales de consumo. Afirma, a este respecto, que "es abusiva, en el sentido del artículo 3.1 de dicha Directiva, una cláusula que figura en las condiciones generales de venta de un profesional, que no ha sido negociada individualmente, e induce a error a dicho consumidor dándole la impresión de que únicamente se aplica al contrato la ley del citado Estado miembro, sin informarle de que le ampara también, en virtud del artículo 6, apartado 2, del Reglamento Roma I, la protección que le garantizan las disposiciones imperativas de la ley de su país de residencia habitual; siendo el órgano jurisdiccional nacional quien debe comprobar estos extremos" ${ }^{\text {"73 }}$.

\section{Conclusiones}

39. La fiducia inmobiliaria es una operación compleja que se caracteriza por el fenómeno de la conexidad o agrupamiento contractual. Aunque el «contrato de fiducia» (en sentido estricto) se celebra únicamente entre fiduciante y fiduciario, los «entramados fiduciarios de carácter inmobiliario» responden a un marco mucho más amplio, resultando de la combinación de numerosas relaciones jurídicas de distinta naturaleza (contractual, societaria, ...) que presentan un nexo funcional entre sí. La principal cuestión que plantean estos entramados en sede conflictual es, sin lugar a dudas, la determinación de la ley aplicable. En este sentido, se debe descartar una determinación global de la misma, y calificar separadamente cada una de las relaciones jurídicas que integran dicho entramado. Resulta crucial delimitar entre las cuestiones de carácter contractual (que pertenecen al ámbito de aplicación de la lex contractus y, por ende, del citado Reglamento Roma I) y las de carácter societario (excluidas del ámbito material de dicho instrumento normativo).

40. La exclusión contemplada en el artículo 1.2.f) del Reglamento únicamente se refiere a los «aspectos orgánicos de esas sociedades», esto es, a los «actos pertenecientes al Derecho de sociedades», entendiendo por tales todos los actos necesarios para la constitución de una sociedad o que rigen su vida interna o su disolución. Con otras palabras, se excluyen aquellas cuestiones que queden comprendidas en el ámbito de la lex societatis.

Los negocios fiduciarios, particularmente, pueden plantear cuestiones pertenecientes al Derecho de sociedades, tales como la condición o no de socios de los fiduciantes, los eventuales derechos y obligaciones que los fiduciantes tienen frente a las sociedades comanditarias, las eventuales obligaciones de los fiduciantes frente a terceros acreedores de la sociedad, así como los estatutos de la sociedad fiduciaria.

\footnotetext{
71 A.L. Calvo Caravaca y J. Carrascosa González, Tratado..., op. cit., pp. 3332-3333.

72 STJUE de 28 julio de 2016, Verein für Konsumenteninformation (C-191/15, EU:C2016:612).

73 C.M. CAAmiña Domínguez, "El consumidor...", op. cit., pp. 177-180.
} 
41. No obstante, la mera circunstancia de que un contrato fiduciario tenga vínculos con cuestiones societarias no tiene por efecto excluir del ámbito material del Reglamento las obligaciones que tienen su origen en dicho contrato.

42. Una vez se ha concluido que la ley aplicable a las obligaciones que tienen su origen en contratos fiduciarios se determina de conformidad con las normas de conflicto de leyes previstas en el Reglamento Roma I, ha resultado necesario responder a la siguiente pregunta: si los contratos fiduciarios que tienen por objeto la administración de participaciones en fondos de inversión inmobiliaria son «contratos de consumo» a los efectos del citado texto. La respuesta será afirmativa siempre que estemos ante un contrato celebrado entre una sociedad fiduciaria (profesional) e inversores (personas físicas) que actúen en calidad de consumidores privados.

43. El artículo 6 del Reglamento Roma I excluye expresamente, en su apartado 4, determinados contratos de su ámbito de aplicación. Particularmente, la letra a) establece que las normas de protección en materia de contratos de consumo no se aplicarán a "los contratos de prestación de servicios cuando los servicios deban prestarse al consumidor, exclusivamente, en un pais distinto de aquel en que el mismo tenga su residencia habitual". De un lado, el Tribunal de Justicia considera que los contratos fiduciarios controvertidos tienen por objeto una prestación de servicios, pues la sociedad TVP ofrece servicios de gestión fiduciaria consistentes en la administración de las participaciones de los inversores, a cambio de una remuneración. No obstante, tales servicios no se han prestado, exclusivamente, en un país distinto de aquel en que el consumidor/inversor tiene su residencia habitual (Austria). De ahí que sí resulten de aplicación las reglas de protección de consumidores previstas en dicho precepto.

44. En los contratos de consumo, las partes pueden elegir la ley aplicable al contrato. No obstante, dicha elección no puede acarrear para el consumidor la pérdida de la protección que le proporcionen aquellas disposiciones que no puedan excluirse mediante acuerdo ("normas imperativas") en virtud de la ley del país en que el consumidor tenga su residencia habitual. Se puede afirmar que la licitud de las cláusulas de elección de ley aplicable insertas en contratos fiduciarios como los controvertidos en el litigio principal, está supeditada a que el contenido de la misma respete la denominada "protección conflictual" prevista en el artículo 6, apartado segundo, del Reglamento, y la protección adicional contemplada en el artículo 3, apartado primero, de la Directiva 93/13/CEE, sobre cláusulas abusivas en contratos celebrados con consumidores. En esta línea, el Tribunal de Justicia reproduce en general la respuesta dada en la sentencia Amazon, en la que establece las reglas de juego entre la Directiva 93/13/CEE y el Reglamento Roma I en materia de contractos internacionales de consumo. Afirma, en este sentido, que es abusiva, en el sentido del artículo 3.1 de dicha Directiva, "una cláusula que figura en las condiciones generales de venta de un profesional, que no ha sido negociada individualmente, e induce a error a dicho consumidor dándole la impresión de que únicamente se aplica al contrato la ley del citado Estado miembro, sin informarle de que le ampara también, en virtud del artículo 6.2 del Reglamento Roma I, la protección que le garantizan las disposiciones imperativas de la ley de su país de residencia habitual. 